\title{
Visual and energy performance of glazed office buildings in Mediterranean climate
}

\author{
Laura Ierardi, Stefania Liuzzi, Pietro Stefanizzi* \\ Polytechnic University of Bari, Via Orabona 4, Bari 70125, Italy \\ Email: pietro.stefanizzi@poliba.it
}

\begin{abstract}
The present study is aimed at analyzing to which extent the type of window glazings affects the energy performance and the indoor comfort of buildings in Mediterranean climate. An office building located in Bari, southern Italy, was assumed as a case study due to its largely transparent envelope. Different glazings were applied to the building: a reflective window, a solar control window with low-E properties and an electrochromic window. The proposed solutions were compared with the existing windows, supposed to be ordinary clear double glazings. Thermal simulations, daylight analysis and economic evaluations were carried out to obtain an all-comprehensive view of the issue, involving energy parameters and comfort indicators. Reports pointed out that on an annual basis the main cost is entailed by cooling needs. The electrochromic window reduces the annual electricity demand for air conditioning by $17 \%$, but its installation costs were found to be not sustainable with reference to the envelope life span. The low-E solar control window succeeds in ensuring the best thermal comfort indoors and in reducing the cost of air-conditioning by nearly $15 \%$, as well as performing slightly better than the reflective glass in terms of electricity demand for lighting.
\end{abstract}

Keywords: Glazed Envelope, Simulation, Thermal Comfort, Visual Comfort, Energy Consumption.

\section{INTRODUCTION}

The building envelope plays an important role in both separating and linking the users of the building and the external environment. An energy efficient building envelope should appropriately control thermal energy provided by sunrays, daylight and air exchange. The massive use of transparent surfaces is a delicate issue, because in case of poor design or bad maintenance the drawbacks could easily overcome the advantages that have led to such an architectural choice. Since windows result from the assembly of components with different thermal properties, they are characterized by a complexity in terms of heat flows that makes them a potential weak spot in the envelope performance.

Cannavale et al. [1] show that dynamic tintable glazings are very promising technologies, and that controlling the transmitted energy fraction may contribute significantly to energy savings in buildings. Dynamic tinting gradient can also increase indoor visual comfort, allowing visual interaction with the outside even when operating as a shading system.

Intini et al. [2] evaluated the Carbon Footprint of PVC fenestrations through Life Cycle Analysis and stated that, in the lifetime of the windows, the greatest impact on climate is due to the use of PVC and glass profiles.

Tavares et al. [3] focused on the energy savings that may occur when using electrochromic (EC) windows, as interesting emerging technology alternative to shading devices to control solar gain in buildings located in Mediterranean climates.

Sibilio et al. [4] reviewed experimental studies conducted on full scale electrochromic windows both in field and laboratory tests.

Sicurella et al. [5] propose a statistical approach for the combined evaluation of thermal and visual comfort in freerunning buildings. They reported statistical parameters suited to perform comparisons on a seasonal basis.

Cannistraro et al. [6] discussed the influence of radiative exchanges on the thermal comfort in living and working environments.

Gugliermetti and Bisegna [7] carried out an integrated analysis of EC windows performances in the Mediterranean climate comparing two electrochromic systems characterized by completely different optical and thermal properties.

Mardaljevic et al. [8] show that it is possible to maintain a neutral spectrum of illumination with EC glazing under normal operation if a small proportion of the glazing is kept in the clear state. A theoretical model to predict the daylight spectrum resulting from any arbitrary combination of clear and tinted glazing is described.

Trubiano et al. [9] outline a digital design process based on four different programs for an optimized energy and visual performance of a typical office building.

Al-Ashval and Budaiwi [10] assessed that significant improvement in lighting quality and energy consumption can be achieved by proper integration of daylight and artificial 
lighting in office buildings in hot climate.

Several authors have highlighted the limitations of the known daylight factor compared to other dynamic parameters for assessing contribution of natural light in the living spaces $[11,12]$.

In this work, different glazing solutions for an office building with mainly glazed outer walls has been studied. The study is conducted with attention to the energy consumption for air conditioning, as well as the thermal and lighting comfort with particular regard to natural light used.

\section{METHODOLOGY AND CASE STUDY DESCRIPTION}

This paper is aimed at comparing different window glazings in order to determine the most suitable solution for transparent building envelopes in the Mediterranean climate. In order to study the energy flow through the external walls and windows, many computer simulation programs are available. In this study, DesignBuilder software was used for modeling and analyzing the behavior of the case study, in terms of both energy consumption for air-conditioning and indoor thermal comfort. The selected software tool uses the latest EnergyPlus simulation engine to calculate the energy performance of buildings, as well as the main indoor comfort parameters, and hence it is well suited to the purposes of the present analysis. DesignBuilder allows to easily create a complete model of the whole building geometry and to insert a wide range of useful information about materials, occupancy and technical equipment.

The case study for the proposed analysis is an office building located in the city of Bari, Apulia, on the east coast of southern Italy. The building, which is called "Blocco E", is currently used as the headquarters of the Regional Departments of Apulia. Blocco E is ideally suited for the purpose due to its location, its massive exposure to sunlight and the significant number of wide windows characterizing the building envelope.

\subsection{Description of the building}

Blocco E presents a rectangular ground plan (with a 80 meter long edge and a 44-meter short edge), which is perfectly symmetrical in relation to the axis parallel to the short edge.

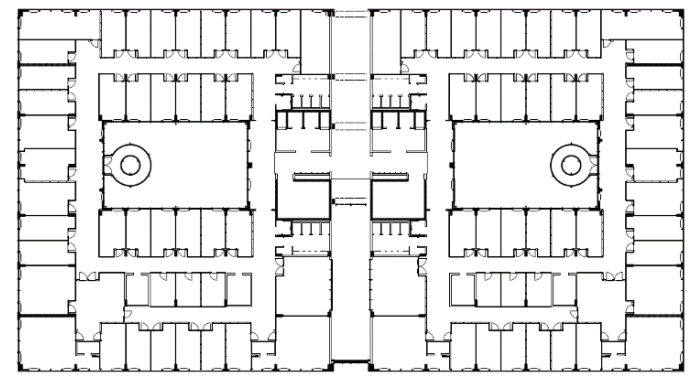

Figure 1. Blocco E, ground plan of the first floor

The building rises to a height of about 12 meters and consists of three floors above ground (PT, P1, P2), where all office rooms are located, and a basement level (PI), used both as storage area and for technical purposes.
The long axis of the ground plan has an east-west orientation; consequently, the long edges face South and North. A wide corridor with a glass ceiling crosses the building in its full height; running along the short axis of the ground plan, it divides the building into two symmetrical blocks and links them at the same time. Each of the blocks has an internal patio, thanks to which the office rooms that are not located by the external façades can obtain fresh air and sunlight.

In the surrounding area there is the so-called "Blocco B", a five-story office building standing about 15 meters south of Blocco E. This distance is large enough that Blocco B does not cast significant shadows on the façade of Blocco E.

The reinforced concrete structure of the building allowed to create a free room layout. Toilets and archives are bounded by brick walls, while other partitions are metallic sandwich panels, constructed in such a way that they can be placed in different positions so that the size of office rooms can be adapted to specific requirements if necessary.

In terms of technical equipment, the building is provided with a mechanical ventilation system and an air-conditioning system that uses both air and refrigerant as working fluids. The thermo-refrigerating station is in the basement and the pipe distribution system supplies fan-coil units in the office rooms. The whole system is electrically powered.

\subsection{Opaque and transparent envelopes}

The building envelope is mainly made of glass, since on each façade the wide windows measure in height approximately as much as the office rooms. The building envelope has a total glazed surface area of $1,715 \mathrm{~m}^{2}$. The intersection between the floor and the external walls is covered by aluminum panels filled with thermal insulating material.

The vasistas-system windows consist of two glass panes separated by an air gap and held in place by simple aluminum frames. Three sides and the corner offices on the north wall are provided with an external solar shading system. It consists of static glass shelves, placed horizontally and held up by a metallic framework.

\subsection{Types of glazing}

Nowadays, the market of glazings offers several solutions to guarantee advanced performance in order to suit demanding application requirements.

The present study aims to solve the critical issues that affect Blocco E by the substitution of the existing windows with higher-efficiency glazings. The new windows have to match specific thermal and daylighting requirements, with the purpose of reducing the electricity consumption and providing a good level of thermal and lighting comfort for users. Due to the area's climate and the use of the building, particular attention was paid to the limitation of heat gains during summer, the heat retain during winter and the illuminance level necessary to enable office workers to perform visual tasks efficiently.

Among the different types of glazing available, the following were investigated:

1. Clear safety window: double glazing composed by safety glass pane on the inner side and a clear soda-lime glass pane on the outer side;

2. Reflective safety window: double glazing composed by a safety glass pane on the inner side and a reflective glass pane on the outer side; 
3. Low-e solar control window: double glazing composed by an inner glass pane with low emissivity properties and a solar control glass pane on the outer side;

4. Electrochromic safety window: double glazing composed by a safety glass pane on the inner side and an electrochromic glass pane on the outer side.

Glass panes were chosen from the wide range of glazings contained in the IGDB [13], a comprehensive international glazing layer database compiled by NFRC. The first composition, provided with aluminum frames with no thermal break, is the pre-existing windows. For the other three solutions a new installation technology was proposed, since the metallic frame was replaced by a new one made of PVC and the cavity between the glass surfaces was filled with Argon gas instead of air. The façade layout was kept in its original setting, as well as the interior distribution of spaces.

\section{THERMAL PROPERTIES OF GLAZINGS}

From a thermal performance perspective, one of the main issues consists in the insulation properties of the building envelope, that highly affects the heating and cooling energy demand of the building.

Table 1 indicates the U-value for each of the glazings investigated, determined by a heat balance calculation on the glazing layers for standard ASHRAE winter conditions in absence of solar radiation.

The response of windows to solar rays hitting the surface at various wavelengths is expressed by different indicators, depending on glazing type, number of panes and any glass coatings. With reference to the whole solar spectrum, three energy indicators are defined: solar absorption is the fraction of radiation absorbed by the surface; solar reflection is the fraction reflected by the surface and solar transmission is the fraction of energy that passes through the surface. A total solar transmission, also called solar heat gain coefficient (SHGC), can be defined as well. It represents the fraction of incident beam solar radiation that enters the zone through the glass, including both the transmitted solar radiation and the inward flowing heat from the solar radiation that is absorbed by the glazing. Table 1 provides overall values calculated on the whole solar spectrum, where transmission data is averaged across all wavelengths, for each of the investigated glazing.

Table 1. Transmission properties of glazings considered

\begin{tabular}{cccc}
\hline & $\begin{array}{c}\mathrm{U}-\text { Value } \\
\mathrm{W} /\left(\mathrm{m}^{2} \mathrm{~K}\right)\end{array}$ & SHGC & Solar transmission \\
\hline $\begin{array}{c}\text { Clear safety } \\
\text { window }\end{array}$ & 2.538 & 0.668 & 0.502 \\
$\begin{array}{c}\text { Reflective safety } \\
\text { window }\end{array}$ & 2.398 & 0.260 & 0.153 \\
$\begin{array}{c}\text { Low-e solar } \\
\text { control window }\end{array}$ & 1.625 & 0.210 & 0.140 \\
$\begin{array}{c}\text { Electrochromic safety } \\
\text { window (intermediate } \\
\text { state 20\%) }\end{array}$ & 1.539 & 0.169 & 0.089 \\
\hline
\end{tabular}

In recent decades, the attention to environmental aspects of architectural design has been steeply increasing and the Italian legislation has been implemented following the framework of the EU directives in terms of energy performance of buildings. The current regulations state the requirements new building must match and the threshold values for performance indicators.
In the climatic area in which Bari is located, the maximum U-value allowed for transparent elements (including frames) in buildings undergoing refurbishment until 2021 is 2.4 $\mathrm{W} / \mathrm{m}^{2} \mathrm{~K}$. This prescription makes clear that the existing glazing does not fulfill the minimum standards for U-value.

\section{MODEL OF THE BUILDING AND THERMAL PERFORMANCE SIMULATIONS}

\subsection{Digital modeling and thermal simulation settings}

Blocco E was modeled using DesignBuilder (Figure 3). Some simplifications were made to make the simulations faster and the output tables more clearly interpretable: the noninsulated mobile partitions were removed because their influence on heat flows was considered negligible; the interior walls that do not constitute closed rooms were removed; the basement, which does not present any windows, is not relevant to the objectives of this study and thus was modeled as a simple empty floor aimed at separating the lower occupied floor from the ground. These expedients do not significantly affect results in terms of heat exchange between spaces at different temperatures or between the building's interior and the outside. The modeling process resulted in an accurate reproduction of the building in its main features.

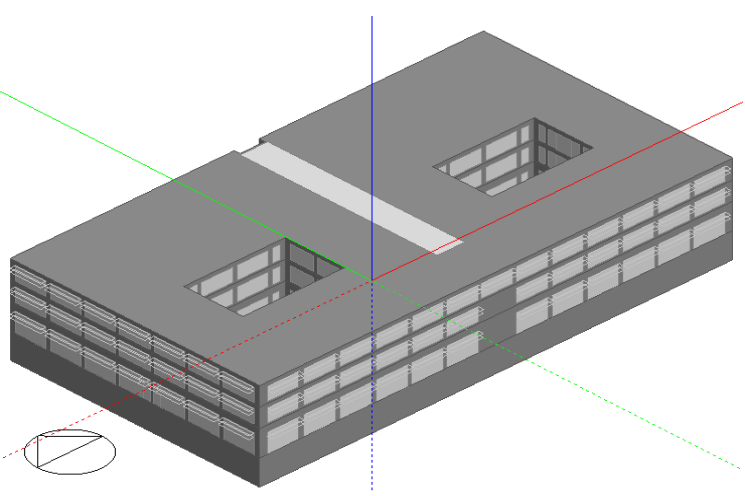

Figure 3. Blocco E modeled using DesignBuilder

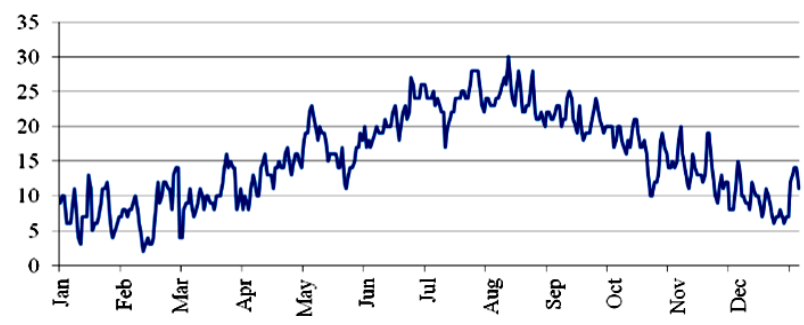

Figure 4. Dry bulb outdoor air temperature $\left[{ }^{\circ} \mathrm{C}\right]$ for the location "Bari/Palese Macchie" (Italy)

The thermal analysis was carried out using the climate data for Bari/Palese Macchie, already present in the database of DesignBuilder. Figures 4-5 show trends for the climate conditions in Bari over the typical solar year. 


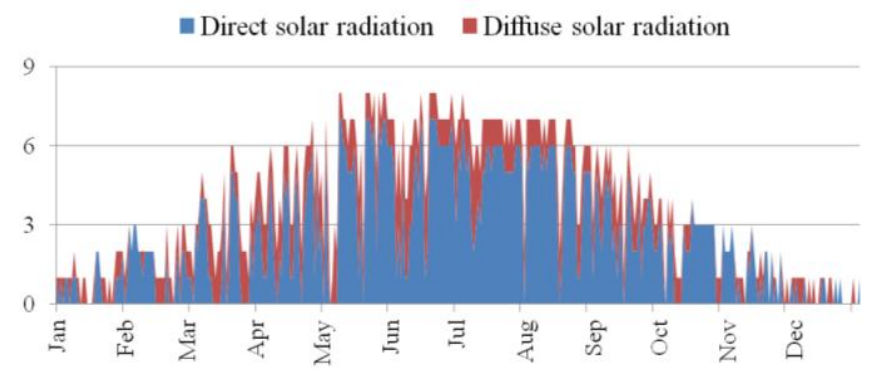

Figure 5. Direct and diffuse solar radiation $[\mathrm{kWh}]$ for the location "Bari/Palese Macchie" (Italy)

DesignBuilder allows to be accurate in terms of occupancy thanks to the activity dialog, where it is possible to indicate the number of users, the type of indoor activity they do, the structure of the typical working week and the heat gains due to office equipment. Moreover, cooling and heating setpoint temperatures can be defined: in this way, an environmental control device automatically turns on and off the airconditioning system on the basis of indoor temperatures.

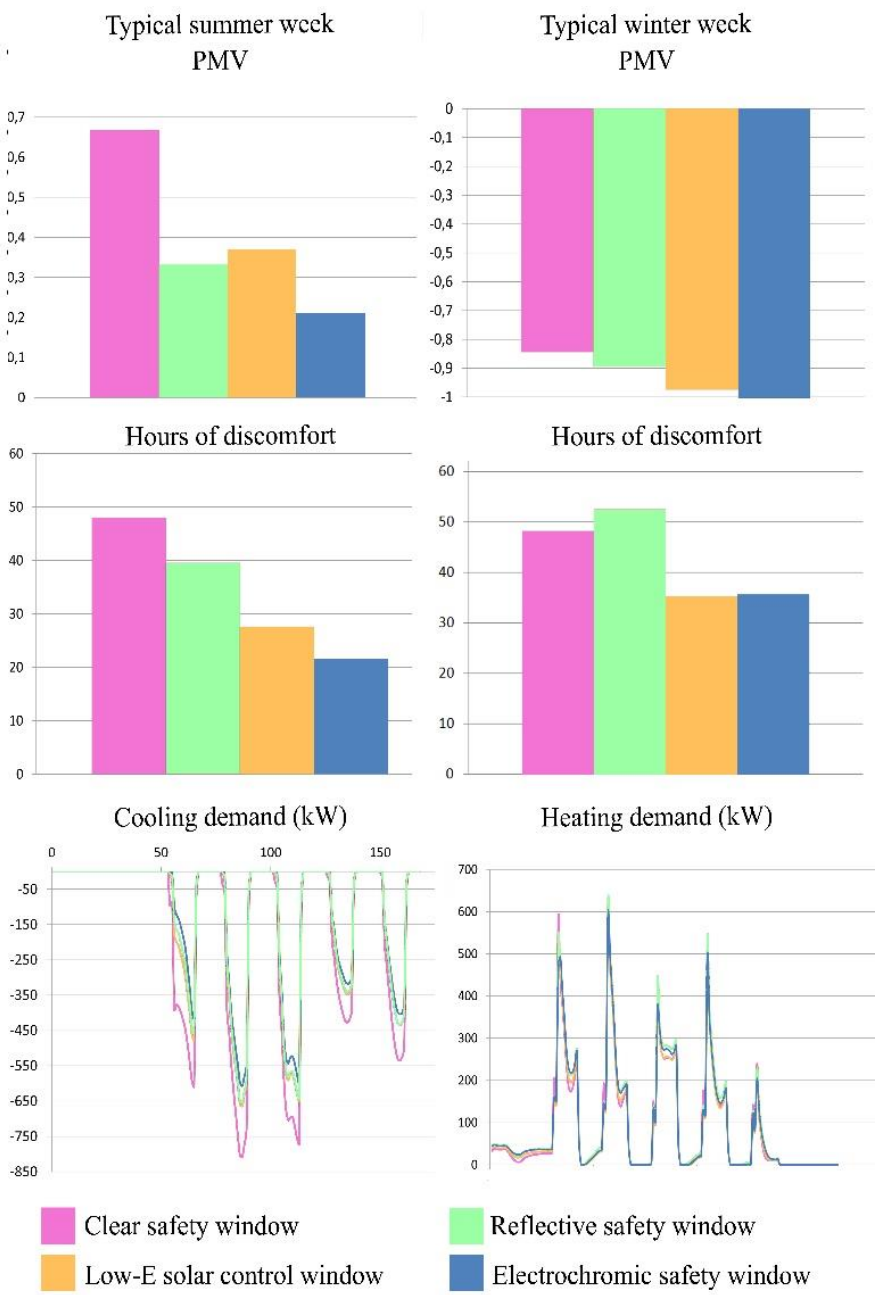

Figure 6. Report of weekly simulations in DesignBuilder

With the aim of better assessing to which extent a suitable window glazing can improve the thermal performance of the building, several simulations were run.

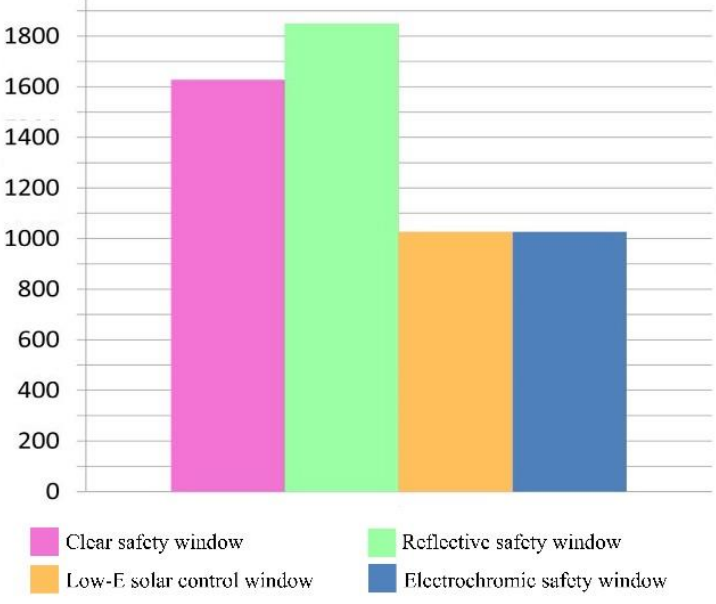

Figure 7. Annual hours of discomfort

Consumption for heating was investigated through a winter simulation, that performs the thermal behavior of the building during the typical winter week (from $22^{\text {nd }}$ December to $28^{\text {th }}$ December), while to analyze consumption for cooling a typical summer week was chosen (from $27^{\text {th }}$ July to $2^{\text {nd }}$ August). Finally, year-round simulations were used to calculate the annual energy consumption for air-conditioning. All the analysis were carried out on a hourly basis. Every simulation was run for each type of window among those proposed.

\subsection{Energy consumption for air conditioning and thermal comfort assessment}

The energy efficiency of the investigated glazings was assessed on the basis of the total consumption for air conditioning, expressed in $\mathrm{kWh}$ per year.

Moreover, since the goal of this paper is achieving the best level of satisfaction with the thermal environment for the users, thermal comfort parameters were calculated. DesignBuilder provides values for PMV, a parameter developed by P. O. Fanger using heat balance equations and empirical studies about skin temperature to express how far from perceived thermal neutrality the actual situation is.

The Predicted Mean Vote (PMV) development was based on the collection of experimental data resulting from the perceptions of a representative sample of people placed in a controlled climate chamber under steady state conditions. Its value varies on a scale from -3 to +3 , on which the comfort range is fixed between $-0,5$ to $+0,5$.

Assessing the amount of time in which users are not satisfied with the thermal environment can be useful as well. For this purpose, DesignBuilder provides data for the total hours of discomfort during the investigated period.

Weekly simulations show that in summer the three proposed solutions perform better than the existing glazing. The electrochromic technology helps reduce at the most the energy demand for cooling purposes and allows to save up to $200 \mathrm{~kW}$, followed by reflective and solar control windows, which have similar behavior. Comfort parameters distribution follows the same trend. In winter, the necessary power for heating and the PMV value do not vary significantly, but the low-e pane and the electrochromic glazing are useful to reduce the total amount of hours of discomfort.

Reports resulting from annual simulations clarify the influence of glazings on the total energy needed for airconditioning, differentiating the data on the basis of cooling 
and heating demand. The total consumption can be reduced with the application of either one of the proposed glazings. Even though existing windows perform well in terms of solar gains and thus does not imply excessive costs for heating, the same goal can be achieved by installing low-E windows that allow reducing the cooling demand as well. Moreover, the low-E and solar control technology reduces the number of discomfort hours during the year, achieving the same comfort level allowed by electrochromic windows.

Table 2 indicates electric energy consumptions for the investigated glazings, having considered for the HVAC system a CoP value of 3 .

Table 2. Annual electricity consumption for air conditioning, obtained with year-round simulations in DesignBuilder

\begin{tabular}{cccc}
\hline & $\begin{array}{c}\text { Electricity } \\
\text { demand } \\
\text { cooling } \\
(\mathrm{kWh})\end{array}$ & $\begin{array}{c}\text { Electricity } \\
\text { demand } \\
\text { heating } \\
(\mathrm{kWh})\end{array}$ & $\begin{array}{c}\text { Total demand } \\
\text { air } \\
\text { conditioning } \\
(\mathrm{kWh})\end{array}$ \\
\hline $\begin{array}{c}\text { Clear safety } \\
\text { window }\end{array}$ & 135,088 & 55,563 & 190,652 \\
$\begin{array}{c}\text { Reflective safety } \\
\text { window }\end{array}$ & 99,344 & 69,279 & 168,623 \\
$\begin{array}{c}\text { Low-e solar } \\
\text { control window }\end{array}$ & 103,166 & 59,424 & 162,590 \\
$\begin{array}{c}\text { Electrochromic } \\
\text { safety window }\end{array}$ & 90,490 & 67,176 & 157,665 \\
\hline
\end{tabular}

\section{ECONOMIC CONVENIENCE EVALUATION}

Even though the new proposed glazings resulted to be more energy efficient than the existing windows, and thus able to reduce the energy demand for heating and cooling, it can also be true that the massive purchase of new windows, for a surface area of nearly $1,715 \mathrm{~m}^{2}$, would entail costs that are not negligible. Hence, a cost-benefit analysis is necessary in order to evaluate whether a substitution of the transparent elements is actually convenient or not, considering the estimated life span of the whole envelope.

It must be specified that in this section only the prices of the glass panes will be considered, without taking in account the cost of frames, because the latter are supposed to be approximately the same for all the solutions proposed, and for the installation, since this would divert the focus of the present study due to the need to include in the evaluation a series of different factor (e.g. transport issues).

\subsection{Net Present Value}

Table 3. Initial costs of the proposed glazings

\begin{tabular}{clll}
\hline & $\begin{array}{l}\text { Unit price } \\
\left(€ / \mathrm{m}^{2}\right)\end{array}$ & $\begin{array}{l}\text { Purchase cost } \\
(€)\end{array}$ & $\begin{array}{l}\text { Initial } \\
\text { cost }(€)\end{array}$ \\
\hline $\begin{array}{c}\text { Clear safety } \\
\text { window } \\
\text { Reflective } \\
\text { safety }\end{array}$ & 65 & 111,475 & \\
$\begin{array}{c}\text { window } \\
\text { Low-e solar } \\
\text { control } \\
\text { window }\end{array}$ & 115 & 145,775 & 34,300 \\
$\begin{array}{c}\text { Electrochromic } \\
\text { safety window }\end{array}$ & 1,000 & $1,715,000$ & $1,603,52$ \\
\hline
\end{tabular}

The initial cost of each solution was calculated as the difference between the purchase cost of the new glazing, derived from the unit price of each pane, and that of the preexisting clear glass (Table 3). Unit prices were taken from [14] except for EC window [15].

Annual cash flows for air conditioning were calculated by considering a price of $0,15 € / \mathrm{kWh}$ for electric energy.

The annual benefit is the difference between the expenditure entailed by the existing glazing and the cost of energy corresponding to each new solution.

Table 4. Annual benefits of the proposed glazings

\begin{tabular}{clll}
\hline & $\begin{array}{l}\text { Consumption fo Expenditure } \\
\text { air conditioning } \\
(\mathrm{kWh} / \mathrm{y})\end{array}$ & $\begin{array}{l}\text { Annual } \\
\text { for air } \\
\text { conditioning } \\
(€ / \mathrm{y})\end{array}$ & $\begin{array}{l}\text { benefit } \\
(€ / \mathrm{y})\end{array}$ \\
\hline $\begin{array}{c}\text { Clear safety } \\
\text { window }\end{array}$ & 190,652 & 28,598 & \\
$\begin{array}{c}\text { Reflective safety } \\
\text { window }\end{array}$ & 168,623 & 25,293 & 3,305 \\
$\begin{array}{c}\text { Low-e solar } \\
\text { control window }\end{array}$ & 162,590 & 24,388 & 4,210 \\
$\begin{array}{c}\text { Electrochromic } \\
\text { safety window }\end{array}$ & 157,665 & 23,650 & 4,948 \\
\hline
\end{tabular}

Annual benefits must be discounted for Net Present Value calculation (1), because of the time span between the purchase of glazings and the expenditure for air conditioning.

$$
\begin{aligned}
& N P V_{n}=I C_{n}+\sum_{t=1}^{N} \frac{B_{n}}{(1+i)^{t}} \\
& \text { (1) } \\
& \mathrm{N} \text { estimated life span of the envelope (40 years); } \\
& \mathrm{i} \text { discount rate }(3,5 \%) .
\end{aligned}
$$

\subsection{Payback period}

When NPV reaches the value of zero, benefits cover the initial costs and consequently it is possible to obtain the payback time (PB) of each solution, which measures the time required for the cash inflows to equal the original outlay.

\begin{tabular}{|c|c|c|}
\hline & $\begin{array}{c}\mathrm{NPV} \\
(€)\end{array}$ & $\begin{array}{l}\mathrm{PB} \\
(\mathrm{y})\end{array}$ \\
\hline $\begin{array}{c}\text { Reflective safety } \\
\text { window }\end{array}$ & 36,265 & 13 \\
\hline $\begin{array}{l}\text { Low-e solar } \\
\text { control window }\end{array}$ & 4,140 & 36 \\
\hline $\begin{array}{l}\text { Electrochromic } \\
\text { safety window }\end{array}$ & $-1,497,624$ & $>40$ \\
\hline
\end{tabular}

Table 5. Net Present Value and Payback time for the proposed glazings

It appears clear that electrochromic window's high initial costs are not repaid by the savings achieved thanks to its energy efficiency, since the payback time period exceeds the estimated life span of the envelope. Conversely, the other two solutions have acceptable payback periods, being nearly 13 years for the Reflective Safety Window and just over 36 years for the Low-E Solar Control Window. 


\section{DAYLIGHT ANALYSIS AND ELECTRICITY CONSUMPTION FOR ARTIFICIAL LIGHTING}

To provide good daylight viewing performance, building glazing must maximize the percentage of sunlight passing through the window in order to allow users to easily perform their visual tasks in the building. A smart use of sunrays can minimize the number of annual operating hours of electric lighting, and thus reduce not only its direct energy demand, but also its associated cooling.

In this study, a daylight analysis was carried out to investigate the suitability of three out of four windows among the abovementioned glazings, since the electrochromic window did not appear cost-efficient for the purpose.

\subsection{Visual properties of glazings}

Visible transmittance is the indicator that describes the amount of light in the visible portion of the spectrum (i.e. with a wavelength between $380 \mathrm{~nm}$ and $780 \mathrm{~nm}$ ) allowed by the glazing material.

The visible transmittance in Table 6 , as it is provided by DesignBuilder, is calculated at normal incidence averaged over the solar spectrum, and weighted by the response of the human eye.

Table 6. Visible transmittance of the selected glazing

\begin{tabular}{ccc}
\hline $\begin{array}{c}\text { Clear safety } \\
\text { window }\end{array}$ & $\begin{array}{c}\text { Reflective safety } \\
\text { window }\end{array}$ & $\begin{array}{c}\text { Low-e solar } \\
\text { control window }\end{array}$ \\
\hline 0.764 & 0.261 & 0.283 \\
\hline
\end{tabular}

\subsection{Visual performance simulation of a single office room}

In order to fulfill the objectives of the study in terms of daylighting, the single office room has been modeled and analyzed using DAYSIM, a Radiance-based program that is able to predict indoor annual luminance and illuminance levels under real-sky conditions derived from statistical weather files [16].

Four models were analyzed, one for each orientation, to investigate the behavior of the different glazings for all the exposure scenarios. All the models were provided with the existing shading system, with the exception of the north-facing office, where there is no shading.

The model's geometry was created with SketchUp (Figure 8 ). The rectangular shaped office room has an indoor area of approximately $16 \mathrm{~m}^{2}$, measuring $2.9 \mathrm{~m} \times 5.5 \mathrm{~m}$, and has a net height of $2.7 \mathrm{~m}$. Such size was chosen on the basis of the actual rooms' dimensions, as illustrated by the ground plan of the first floor of Blocco E. The window has a height of $2.40 \mathrm{~m}$ and is $2.40 \mathrm{~m}$ large, and has been defined as a double glazing. The door that connects the room with the corridor was supposed to give negligible contribution to natural light penetration and was hence omitted in the model. As Daysim calculates its daylight metrics at discrete points, a grid of 180 sensor points was placed on a horizontal mesh at a height of $80 \mathrm{~cm}$ from the floor, which is the typical position of work planes. The distance between two consecutive sensors is $30 \mathrm{~cm}$ on both the grid axes.

DAYSIM generates an annual illuminance profile at each point of interest. Climate data for Bari have been imported in DAYSIM and a simulation time step of 5 minutes has been chosen in order to obtain the daylight parameters for each sensor points as well as the annual electric lighting energy use in the whole investigated zone.

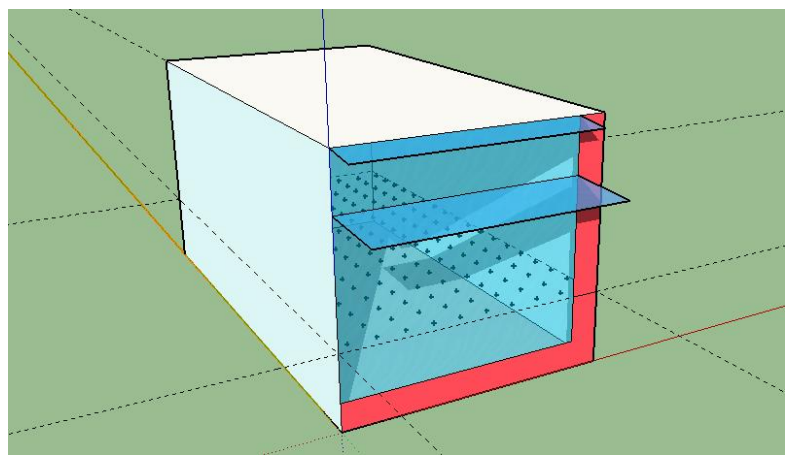

Figure 8. South-oriented office room modeled in Sketchup

Table 7. Site input data for simulations with DAYSIM

\begin{tabular}{cc}
\hline Place description & Bari \\
Latitude & 41.111 \\
Longitude & 16.855 \\
Time zone & 15.0 \\
Site elevation (m) & 16.0 \\
Simulation time step (min) & 5 \\
Ground reflectance & 0.2 \\
\hline
\end{tabular}

The properties of opaque materials were set in SketchUp, while the glazing was modeled in DAYSIM. The software allows to edit the value of visible transmissivity $t_{n}$, which is related to visual transmittance $T_{n}$ by means of the eq. (2).

$$
t_{n}=\frac{\sqrt{0.8402528435+0.0072522239 \cdot T_{n}^{2}}-0.9166530661}{0.0036261119 \cdot T_{n}}
$$

Table 8. Visible transmissivity of the selected glazing

\begin{tabular}{ccc}
\hline $\begin{array}{c}\text { Clear safety } \\
\text { window }\end{array}$ & $\begin{array}{c}\text { Reflective safety } \\
\text { window }\end{array}$ & $\begin{array}{c}\text { Low-e solar } \\
\text { control window }\end{array}$ \\
\hline 0.832378 & 0.284359 & 0.308328 \\
\hline
\end{tabular}

The simulation output depends on the scene complexity chosen for the case study. The default scenario called "Scene complexity 1" is developed to calculate the annual illuminance profile due to daylight at a reference point behind a window in a particular office in a large building, and thus appeared well suited to the purpose of this study.

Table 9 illustrates values for the main input parameters that were used to run DAYSIM simulations.

Table 9. Parameters for DAYSIM year-round simulations

\begin{tabular}{cccc}
\hline Ambient bounces & 5 & Ambient accuracy & 0.1 \\
Ambient division & 1,000 & Minimum illuminance level & 500 \\
Ambient super- & 20 & Installed lighting power & 12 \\
sample & & density & 16 \\
Ambient resolution & 300 & Zone size & 16 \\
\hline
\end{tabular}

\subsection{Electricity consumption and visual comfort indicators}

The glazings were compared on the basis of three comfort parameters, which are useful to assess the internal natural lighting levels as perceived on working planes or surfaces: DF, 
DA and UDI [17, 18].

The Daylight Factor (DF) is the ratio of the indoor illuminance level to the simultaneous light level outside the building, calculated on a horizontal plane from an unobstructed hemisphere of overcast sky (based on the standard CIE "Overcast Sky"). DF indicator is thus expressed in percentage, and a minimum of $2 \%$ is advised in case of visual tasks such as reading or writing.

The Useful Daylight Illuminance (UDI), introduced by Nabil et al. [19], is a parameter based on absolute daylight illuminance levels calculated on meteorological data collected over the solar year. UDI indicates the percentage of time in which the daylight illuminance falls within a comfort range, which was defined between 100 and 2000 lux. Current technical regulations advise for ordinary offices a minimum illuminance level of 300-500 lux, that rises to 1000 lux for more intense visual tasks. For this reason, in DAYSIM a minimum illuminance level of 500 lux was set: when daylight cannot provide the necessary level, the electrical lighting is turned on.

The Daylight Autonomy (DA) represents the percentage of occupied hours in a year where daylighting is met by natural light alone.

Figure 9 shows the distribution of DF and DA in the typical south-facing office room provided with the Clear Safety Window. It is evident the different evaluation of the daylight available as estimated by the two parameters. DA is a more correct estimate of the daylight available in the environment during the working hours all over the year.

The values of DF, UDI and DA along the axis normal to the window on the working plane for South orientation (left) and North orientation (right) are reported in Figure 10

Analyzing the simulation reports, some remarks have to be pointed out:

1) Higher values of DF are present in North orientation due to the absence of screens in the North façade;

2) High values of illuminance near the window in South orientation make UDI falling down;

3) Above $80 \%$ of time an illuminance between 100 and 2000 lux is ensured across the room;

4) The DA distribution indicates that, beyond the distance of 2 meters from the window, the natural light is insufficient, and thus integration with artificial light is required.

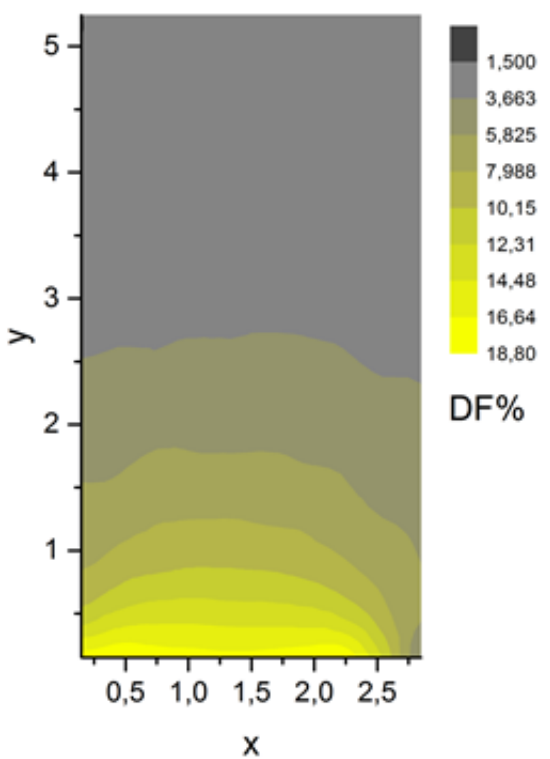

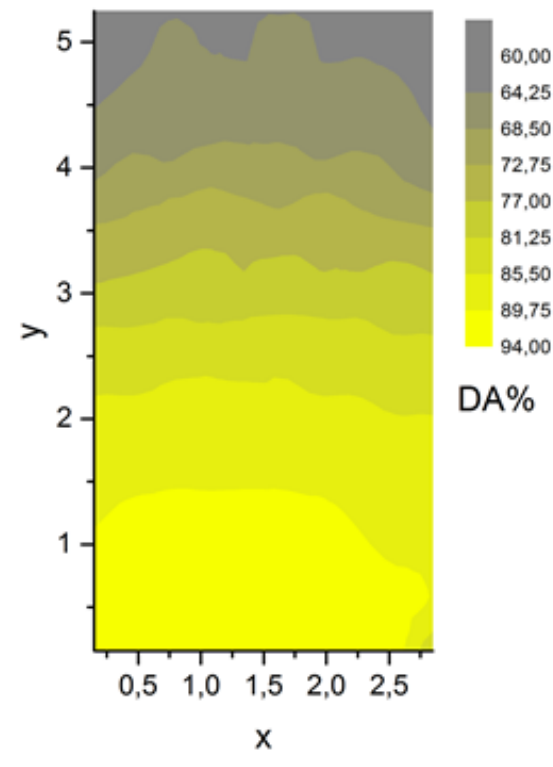

Figure 9. Daylight Factor (top) and Daylight Autonomy (bottom) in South-oriented office room with clear safety window
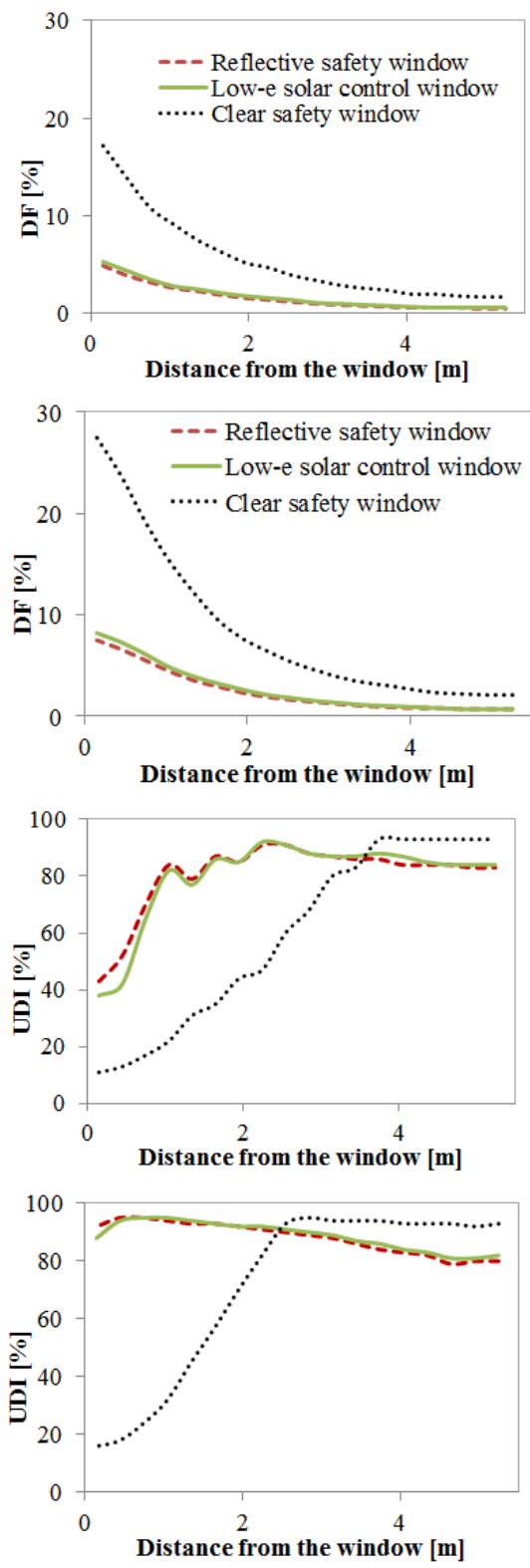

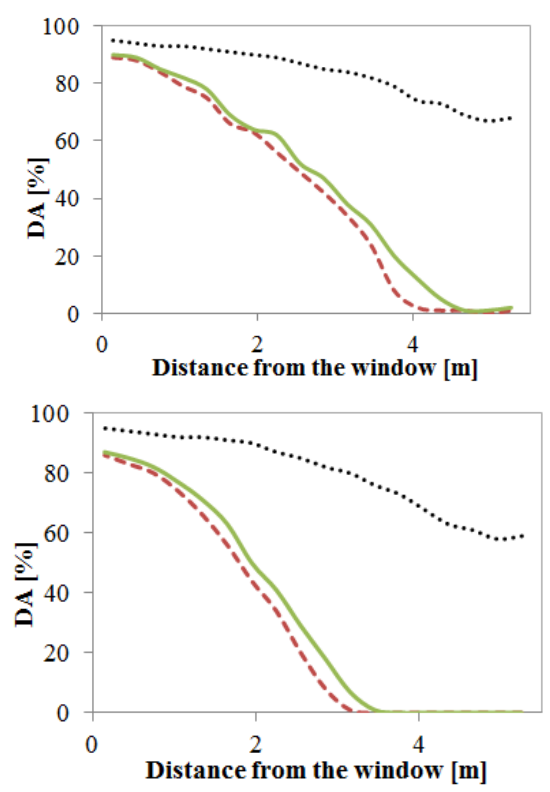

Figure 10. DF, UDI and DA values along the axis normal to the window on the working plane for South orientation (left) and North orientation (right)

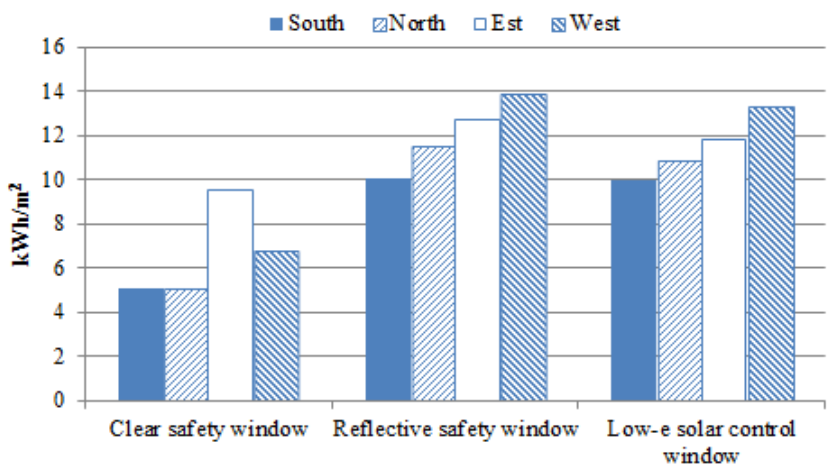

Figure 11. Total annual lighting energy use

DAYSIM simulation outputs in terms of total annual lighting energy use (Figure 11) show that the existing windows entail the lowest electricity consumption, especially for South and North orientation, while the highest is reached with the Reflective Safety Window in West-facing rooms.

\section{CONCLUSIONS}

In order to assess the most suitable glazing for the case study, the different analysis conducted led to different results, pointing out the relevance of an all-comprehensive approach to the problem. Even though the electrochromic glass ensures the lowest energy consumption for air-conditioning (with a reduction of annual costs by $17 \%$ ), the payback period of its installation on such a large surface was found to exceed the acceptable limits. The reflective window has the shortest payback period, but it entails an increase in the number of thermal discomfort hours and slightly major costs in terms of electric lighting. For the case study, the best solution appears to be the Low-E Solar Control Window, since it appears to perform as well as the electrochromic one in terms of thermal comfort, to reduce the costs for air-conditioning by $14.7 \%$ and to ensure lower costs for artificial lighting.

\section{ACKNOWLEDGEMENT}

L. Ierardi author sincerely thanks the members of the staff of "Trait d'Union srl" for their support in providing information and geometrical data about the case study.

\section{REFERENCES}

[1] Cannavale A., Martellotta F., Ayr U. (2008). Nanodevices and novel materials for energy-efficient constructions, Energy Procedia, Vol. 101, pp. 113-120. DOI: $\underline{\text { 10.1016/j.egypro.2016.11.015 }}$

[2] Intini F., Rospi G., Cardinale N., Kühtz S., Dassisti M. (2016). Life cycle assessment of Italian residential windows: Sensitivity of analysis, Int J Heat \& Tech, Vol. 34, No. Sp. 2, pp. S235-S241. DOI: 10.18280/ijht.34S207

[3] Tavares P.F., Gaspar A.R., Martins A.G., Frontini F. (2014). Evaluation of electrochromic windows impact in the energy performance of buildings in Mediterranean climates, Energy Policy, Vol. 67, pp. 6881. DOI: $10.1016 /$ j.enpol.2013.07.038

[4] Sibilio S., Rosato A., Scorpio M., Iuliano G., Ciampi G., Vanoli G.P., de Rossi F. (2016). A review of electrochromic windows for residential applications, Int J Heat \& Tech, Vol. 34, No. Sp. 2, pp. S481-S488. DOI: $\underline{10.18280 / i j h t .34 S 241}$

[5] Sicurella F., Evola G., Wurtz E. (2012). A statistical approach for the evaluation of thermal and visual comfort in free-running buildings, Energy and Buildings, Vol. 47, pp. 402-410. DOI: 10.1016/j.enbuild.2011.12.013

[6] Cannistraro G., Cannistraro M., Restivo R. (2015). Some observations on the radiative exchanges influence on thermal comfort in rectangular open-space environments, Int J Heat \& Tech, Vol. 33, pp. 79-84. DOI: $\underline{10.18280 / \text { ijht.330213 }}$

[7] Gugliermetti F., Bisegna F. (2003). Visual and energy management of electrochromic windows in Mediterranean climate, Build Environ, Vol. 38, pp. 479-92. DOI: $\underline{\text { 10.1016/S0360-1323(02)00124-5 }}$

[8] Mardaljevic J., Kelly Waskett R., Painter B. (2016). Neutral daylight illumination with variable transmission glass: Theory and validation, Lighting Res. Technol., Vol. 48, No. 3, pp. 267-286. DOI: $10.1177 / 1477153515620339$

[9] Trubiano F., Roudsari S.M., Ozkan A. (2013). Building simulation and evolutionary optimization in the conceptual design of a high-performance office building, Proceedings of IBPSA/BS 2013, pp. 13061314.

[10] Al-Ashwal N.T., Budaiwi I.M. (2011). Energy savings due to daylight and artificial lighting integration in office buildings in hot climate, Int. J. of Energy and Environment [Online], Vol. 2, No. 6, pp. 999-1012.

[11] Carlucci S., Causone F., De Rosa F., Pagliano L. (2015). A review of indices for assessing visual comfort with a view to their use in optimization processes to support building integrated design, Renewable and Sustainable Energy Reviews, Vol. 47, pp. 1016-1033. DOI: 10.1016/j.rser.2015.03.062

[12] Mardaljevic J., Heschong L., Lee E. (2009). Daylight metrics and energy savings, Lighting Res. Technol., 
Vol. 41, pp. 261-283. DOI: $\underline{10.1177 / 1477153509339703}$

[13] IGDB (2017). International Glazing Database, Retrieved from http://windows.lbl.gov/materials/IGDB/.

[14] DEI Tipografia del Genio Civile (2016). Prezzario nuove costruzioni, (in Italian).

[15] http://www.shepwayglass.co.uk/glass/switchableprivacy-glass.aspx. Accessed April 2017.

[16] Reinhart C.F. (2006). Tutorial on the use of daysim simulations for sustainable design, Institute for Research in Construction, National Research Council Canada.
[17] Reinhart C.F., Walkenhorst O. (2001). Dynamic RADIANCE-based daylight simulations for a full-scale test office with outer venetian blinds, Energy and Buildings, Vol. 33, No. 7, pp. 683-697. DOI: 10.1016/S0378-7788(01)00058-5

[18] Reinhart C.F., Mardaljevic J., Rogers Z. (2006). Dynamic daylight performance metrics for sustainable building design, Leukos, Vol. 3, No. 1, pp. 7-31.

[19] Nabil A., Mardaljevic J. (2005). Useful daylight illuminance: a new paradigm to access daylight in buildings, Lighting Res Tech, Vol. 37, No. 1, pp. 41-59. DOI: $10.1191 / 13657828051$ li128oa 